\title{
Research Progress on Leucine-Rich Alpha-2 Glycoprotein 1: A Review
}

\author{
Yonghui Zou ${ }^{1,2 \dagger}$, Yi Xu ${ }^{1,2 \dagger}$, Xiaofeng Chen ${ }^{1,2 \dagger}$, Yaoqi Wu ${ }^{1,3}$, Longsheng $\mathrm{Fu}^{1}$ and Yanni $\mathrm{Lv}^{1 *}$ \\ ${ }^{1}$ Department of Pharmacy, The First Affiliated Hospital of Nanchang University, Nanchang, China, ${ }^{2}$ School of Clinical Medicine, \\ Nanchang University, Nanchang, China, ${ }^{3}$ College of Pharmacy, Nanchang University, Nanchang, China
}

\section{OPEN ACCESS}

Edited by:

Syed Nasir Abbas Bukhari,

Al Jouf University, Saudi Arabia

Reviewed by: Madoka Nakajima,

Juntendo University, Japan Shinichiro Shinzaki,

Osaka University, Japan

*Correspondence:

Yanni LV

yannilv225@ncu.edu.cn

${ }^{t}$ These authors have contributed equally to this work

Specialty section:

This article was submitted to Experimental Pharmacology and Drug

Discovery,

a section of the journal

Frontiers in Pharmacology

Received: 04 November 2021

Accepted: 13 December 2021

Published: 05 January 2022

Citation:

Zou Y, Xu Y, Chen X, WU Y, Fu L and Lv Y (2022) Research Progress on Leucine-Rich Alpha-2 Glycoprotein 1:

A Review.

Front. Pharmacol. 12:809225. doi: $10.3389 /$ fphar.2021.809225
Leucine-rich alpha-2 glycoprotein 1 (LRG1) is an important member of the leucine-rich repetitive sequence protein family. LRG1 was mainly involved in normal physiological activities of the nervous system, such as synapse formation, synapse growth, the development of nerve processes, neurotransmitter transfer and release, and cell adhesion molecules or ligand-binding proteins. Also, LRG1 affected the development of respiratory diseases, hematological diseases, endocrine diseases, tumor diseases, eye diseases, cardiovascular diseases, rheumatic immune diseases, infectious diseases, etc. LRG1 was a newly discovered important upstream signaling molecule of transforming growth factor- $\beta$ (TGF- $\beta$ ) that affected various pathological processes through the TGF- $\beta$ signaling pathway. However, research on LRG1 and its involvement in the occurrence and development of diseases was still in its infancy and the current studies were mainly focused on proteomic detection and basic animal experimental reports. We could reasonably predict that LRG1 might act as a new direction and strategy for the treatment of many diseases.

Keywords: LRG1, review, TGF- beta 1, nervous, tumor

\section{INTRODUCTION}

The incidence of refractory chronic diseases is increasing year by year, and this is always a challenging aspect of medical work. Increasing numbers of studies have found that leucine $\alpha-2$ glycoprotein-1 (LRG1) engaged in signal transduction and pathogenensis of multiple diseases. Leucine-rich a2-glycoprotein 1 (LRG1), first separated from human serum in 1977, is a family member of the leucine-rich repeating family, consisting of eight leucine-rich repeats (mostly 20-30 amino acid residues in length) (Liu et al., 2017). The LRG1 gene located on the short arm of chromosome 19, band 3, and region 13 (19P13.3). The mature form of LRG1 is a secreted protein isolated from human serum (Haupth and Baudner, 1977), while its amino acid sequence was determined in 1985 with 312 amino acids (Takahashi et al., 1985). The molecular weight of LRG1 is $45 \mathrm{kD}$, and its equipotential point is $4.52-4.72$. The initial studies have demonstrated that most leucine-rich repeat proteins were detected with high expression as transmembrane proteins in the central nervous system, which mainly played role in the normal physiological activities of the nervous system, such as synapse formation, synapse growth, the development of nerve processes, neurotransmitter transfer and release, and cell adhesion molecules or ligand binding proteins. The expression of LRG1 could be detected in disease specimens, and LRG1 expression had also been detected in the blood of patients, and it had relatively stable specificity and sensitivity. LRG1 could act as a new biological marker for inflammatory diseases and some tumors, which was very important for the diagnosis and prognostication of diseases (Figure 1). It has been reported that LRG1 mainly exerted its 


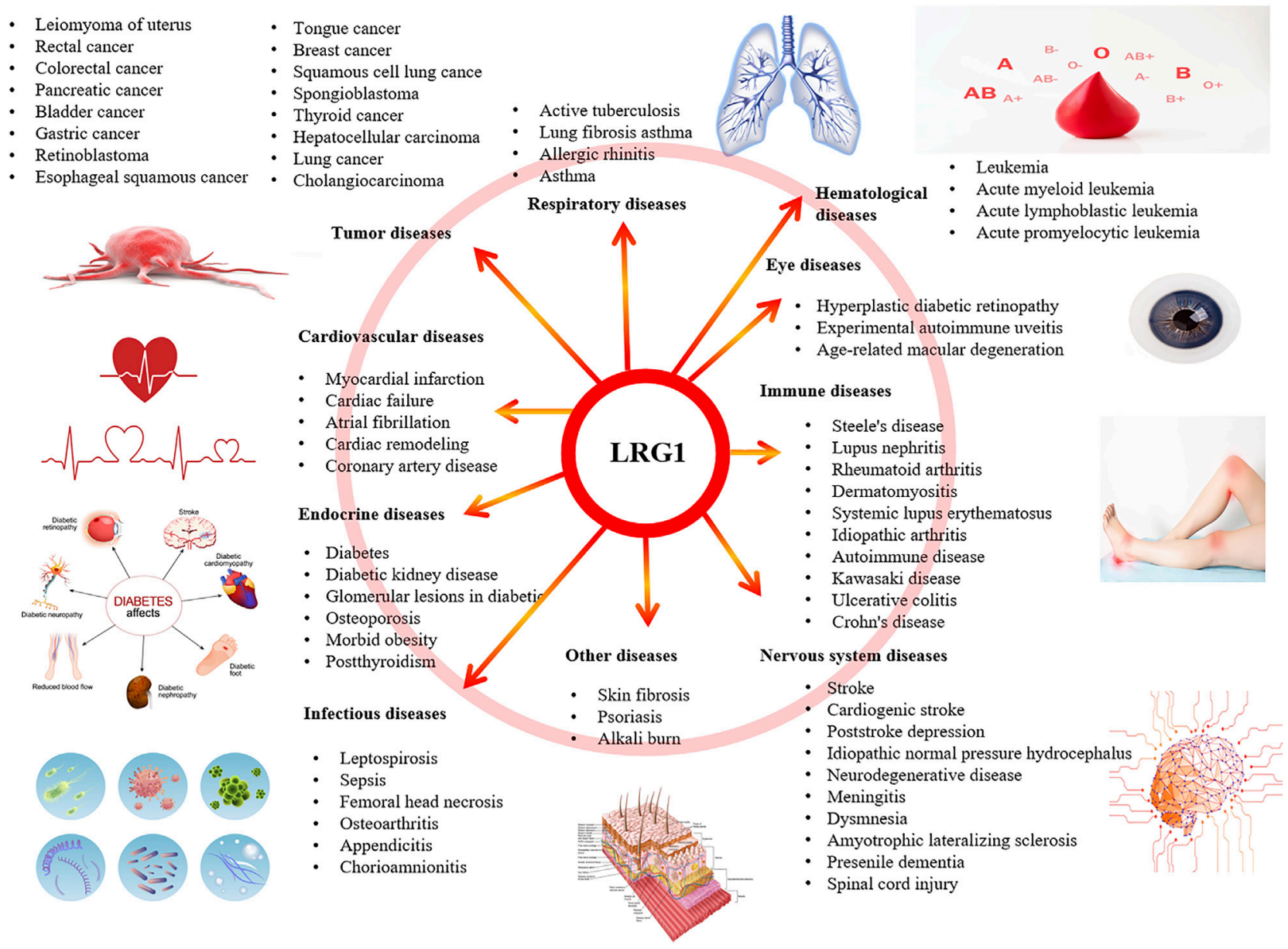

FIGURE 1 | LRG1 involved in the related diseases.

functions through the transforming growth factor- $\beta$ (TGF- $\beta$ ) pathway. This review expected to describe the full implication of the LRG1 in related diseases.

\section{Part One: LRG1 Involved in Respiratory Diseases}

Findings in clinical respiratory diseases suggested that LRG1 was a promising biomarker for the detection of active tuberculosis, lung fibrosis, asthma, allergic rhinitis, and asthma. LRG1 serum levels in tuberculosis patients were significantly higher than those in healthy controls group, and decreased after 1 month of antitubercular therapy (Fujimoto et al., 2020). Inhibitory actions of allergens responsible for allergic airway disorders might reduce levels of LRG1 and transforming growth factor beta receptor II in patients.(Hao L. et al., 2016). In basic research related with respiratory related diseases, LRG1 promoted lung fibrosis by regulating the phosphorylation of TGF- $\beta$ and smad2 in the profibrotic activation of fibroblast (Honda et al., 2017). LRG1 was highly expressed in a subpopulation of bronchial epithelial cells in asthma model mice (Honda et al., 2016). A pathway that inhibition of LRG1 might rescue vascular rarefaction and alveolar regression for the treatment of chronic obstructive pulmonary disease or emphysema (Hisata et al., 2021).

\section{Part Two: LRG1 Involved in Hematological Diseases}

LRG1 was found to be important in hematological diseases, and the association was primarily with leukemia. Bioinformatics analysis revealed that some proteins, namely, LRG1, S100A8, SPARC (secreted protein acidic and rich in cysteine), and sL-selectin (human recombinant soluble L-selectin) were closely related to childhood T-cell acute lymphoblastic leukemia and acute promyelocytic leukemia (Yu R. et al., 2019; Yu, Zhang, et al., 2021). On hematological diseases cellular model, healthy hematopoietic stem progenitor cells overexpressed the leukemia stem cell-specific genes LY86, LRG1, and PDE9A under the induction of leukemia microvesicles (Razmkhah et al., 2019). The silencing of LRG1 could reduce viability and promote apoptosis in leukemia KASUMI-1 cells through regulating cyclin and apoptosis-related proteins (Xiao and Zhu, 2018). In addition, alpha-2-HS-glycoprotein and LRG1 were the most prospective candidates for different myelodysplastic syndrome 


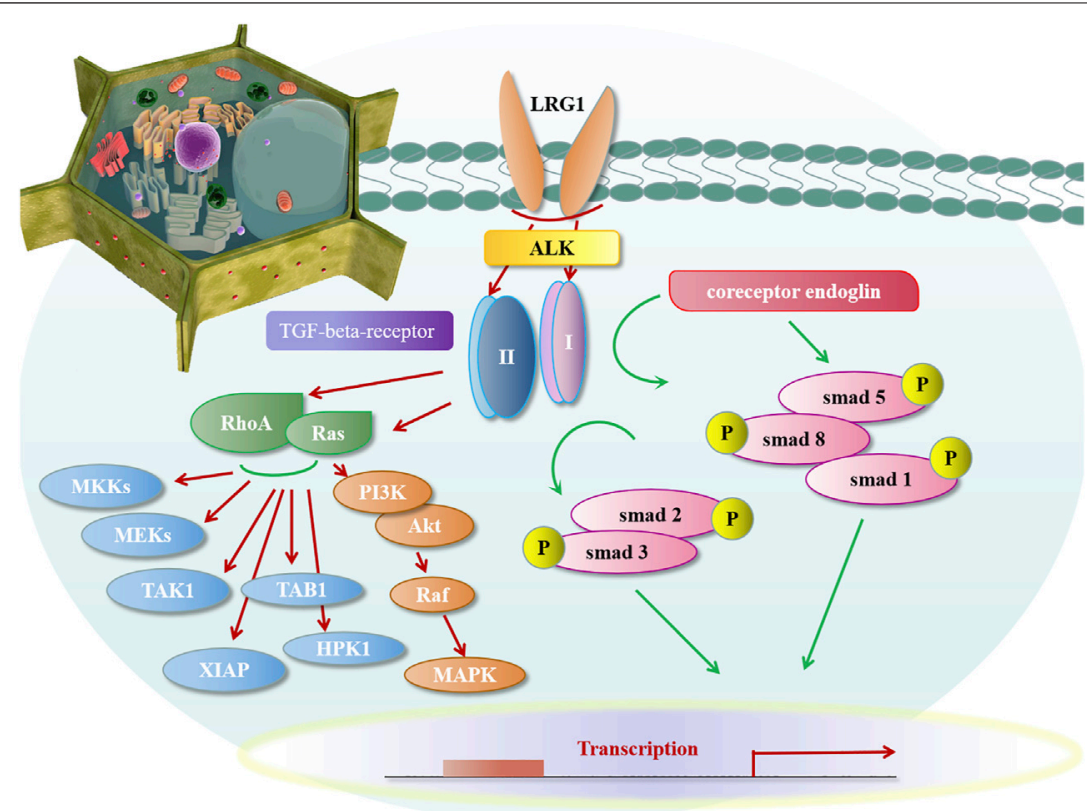

FIGURE 2 | LRG1 activated TGF- $\beta$ signaling pathway

subgroups, including refractory cytopenia with multilineage dysplasia, refractory anemia or refractory anemia with ringed sideroblasts, etc (Majek et al., 2015).

\section{Part Three: LRG1 Involved in Endocrine Diseases}

LRG1 could be further excavated as a potential target for the pathological progress of diabetic kidney disease, including glomerular lesions in diabetes (Fu et al., 2018; Liu J.-J. et al., 2021; Iqbal et al., 2021), lysosomal function related Type 1 diabetes (Singh et al., 2017), and nephropathy in type 2 diabetes. (Liu et al., 2017; Gurung et al., 2021). Among Asian patients with type 2 diabetes, low baseline skeletal muscle mass was tightly related with the growing risk of chronic kidney disease progression. Pigment epithelial-derived factor and LRG1 mediated a negative association between skeletal muscle mass index and chronic kidney disease in Asians with progression to type 2 diabetes (Low et al., 2021). Knockdown of LRG1 might significantly ameliorate diabetesinduced diabetic glomerulopathy, podocyte loss, and glomerular angiogenesis, while its mechanism was connected with the activation of ALK1 (activin receptor-like kinase)-smad1/5/8 in the glomeruli of diabetic mice (Hong et al., 2019). Glomerular LRG1 expression was enhanced in $\mathrm{db} / \mathrm{db}$ mice, accompanied by higher expressed glomerular fibrosis associated genes compared with that in nondiabetic $\mathrm{db} / \mathrm{m}$ mice (Haku et al., 2018).

In addition, patients with diabetes are at high risk of complications from cardiac, cancer, and angiogenesis outcomes. Plasma LRG1 might potentially be involved in the pathogenesis of heart failure in type 2 diabetes patiens (Liu J. J. et al., 2021). Several biomarkers consisting of apolipoprotein A-IV, monocyte differentiation antigen CD14, and LRG1 demonstrated their influences on the differentiation between diabetes and early pancreatic cancer (Peng et al,, 2020). LRG1 was a novel proangiogenic factor involved in abnormal angiogenesis and renal fibrosis in diabetic nephropathy (Zhang A. et al., 2020). LRG1 promoted wound repair and regenerate nerves of diabetic corneal epithelium by regulating matrix metalloproteins ( $\mathrm{Li}$ et al., 2020).

Furthermore, LRG1 was involved in other endocrine diseases and has key capabilities for the pathological process of diseases. LRG1 could be applied as a biomarker to detect glomerular damage in kidney disease (Lee et al., 2018; Jiang et al., 2020). Serum LRG1 participated in the prediction of the mortality of cardiovascular morbidity complication in end-stage renal disease patients (Yang FJ. et al., 2020). Weight loss after metabolic/bariatric surgery was connected with low level of plasma LRG1, suggesting it is a potential biomarker of inflammation and obesity (Pek et al., 2018). The increased proteins of haptoglobin, hemopexin, and LRG1 were found from hyperthyroidism patients with the treatment of antithyroid (Masood et al., 2020). LRG1 downregulation promoted osteoblast viability and collagen synthesis by activating the TGF- $\beta /$ smad signaling pathway (Gu et al., 2020).

\section{Part Four: LRG1 Involved in Tumor Diseases}

Tumors are serious diseases endangering people's lives, and their early diagnosis and targeted treatment have become hotspots of research (Chen et al., 2016). Reports on the relationship between intestinal cancer and LRG1 have rapidly increased in the last 5 years. LRG1 response to preoperative chemoradiotherapy might help in prognostication and the selection of treatments after preoperative chemoradiotherapy (Lee et al., 2019). LRG1 with fucosylated triantennary $\mathrm{N}$-glycan were detected as a new combined colorectal cancer marker, which had higher sensitivity exceeding CA19-9 (Shinozaki et al., 2018). Additionally, LRG1 served as a biomarker to detect early high-risk adenomas as well as colorectal cancer (Sun et al., 2017; Komor et al., 2020; Kopylov 
et al., 2020). significantly decreased combined indexes of stem cell factor, LRG1, and platelet lymphocyte ratio could be detected in nontreated colorectal cancer patients (Fouda et al., 2021). Basic research results suggested that LRG1 promoted the cellular proliferation and apoptosis by modulating runt-related transcription factor 1 expression in colorectal cancer (Zhou et al., 2017). Extracellular vesicles derived from serum in colon cancer might promote metastasis through the modulating of extracellular matrixrelated proteins, secreted protein acidic and rich in cysteine, and LRG1 (Zhong et al., 2019). Long noncoding RNA prostate miR-150-5p/ LRG1 pathway facilitated the malignant progression of colorectal cancer and might provide a targeted colorectal cancer therapy (Lou et al., 2020). LRG1 could promote the cellular invasion and growth, which might act as the outcomes of colorectal cancer patients (Zhang et al., 2018).

LRG1 was identified as a biomarker for tumors of the digestive system. In addition to intestinal cancer, LRG1 could act as the biomarker for esophagus cancer, gastric carcinoma, and bile duct cancer, etc. Overexpression of LRG1 negatively regulated TGF- $\beta$ signaling pathways to inhibite cellular migration and invasion of esophageal squamous (Zhang N. et al., 2020). LRG1 was an independent indicator of poor clinical outcomes in esophageal squamous cell carcinoma (Wang et al., 2019). Combound biomarker of LRG1 and C-reactive protein and soluble interleukin-6 receptor could forecast the response to preoperative chemoradiotherapy in esophageal cancer patients (Nambu et al., 2019). Serum LRG1 of gastric cancer patients was significantly higher than that of healthy volunteers, and increased with the progression of gastric cancer pathological stage (Yamamoto et al., 2017). The upregulation of LRG1 associated with TGF- $\beta 1$ expression served as an independent factor for patients with postoperative intrahepatic cholangiocarcinoma (Jin et al., 2020). A metabolite panel in combination with CA19-9, tissue inhibitor of metalloproteinase 1, and LRG1 exhibited substantially improved performance in the detection of earlystage pancreatic ductal adenocarcinoma (Fahrmann et al., 2019). Prediagnostic cases below the cutoff value for CA19-9, in combination with LRG1 and TIMP1, was identified as useful for the early detection of pancreatic cancer (Choi et al., 2021; Fahrmann et al., 2021); also, these results were strongly supported in a pancreatic cancer animal model (Fukamachi et al., 2019; Harlid, Gunter, and Van Guelpen 2021; Lee et al., 2021). Molecular mechanistic research hinted that LRG1 strong enhance the cellular migration and invasion of pancreatic ductal adenocarcinoma cells in vitro through activation of the p38/MAPK signaling pathways (Xie ZB. et al., 2019).

Outside tumors of the digestive system, LRG1 was found to be the biomarker in other tumor diseases. For isocitrate dehydrogenase one wild-type glioblastoma, high expression of LRG1 was regarded as an independent factor (Furuta et al., 2020). The plasma concentrations of LRG1, C-reactive protein, and complement component C9 showed significant positive correlations with tumor size in glioblastoma patients (Miyauchi et al., 2018). MiR-335 regulated LRG1 and positively suppressed the invasion of neuroblastoma cells (Lynch et al., 2012). Elevation expression of LRG1 and decreased Ki-67 were showed by SET domain-containing 1A histone lysine methyltransferase knockdown. Enhanced expression of LRG1 in Hs578T might distinguish poor outcomes from triple-negative breast cancer (Mohamad Hanif 2019). Abnormal high expression of LRG1 levels promoted lymphatic metastasis and cellular apoptosis in the malignant progression of breast cancer (Zhang YS. et al., 2021; Jemmerson et al., 2021). LRG1 alone or in combination with CA125 might be a stool biomarker in the diagnosis of epithelial ovaries (Wu et al., 2015).

Recent advances in the interpretation of the molecular mechanism of LRG1 in tumor indicated that long noncoding RNA taurine upregulated one mediated endothelial angiogenesis through the LRG1/TGF- $\beta$ pathway (Fan et al., 2019), which could predict clinical outcomes after transarterial chemoembolization (Peng et al., 2020). Elevated serum levels of TGF- $\beta 1$ and LRG1 were associated with morbidity and severity of uterine leiomyoma (Kamalipooya et al., 2021). Other findings imply that LRG1 was correlated with the diagnosis of squamous cell carcinoma of the head and neck (Wang et al., 2017a), tongue carcinoma (Hao L. J. et al., 2016), oral cancer (Chang et al., 2019), retinoblastoma (Luan et al., 2021), thyroid carcinoma (Ban et al., 2019), hepatocellular carcinoma (Yu et al., 2017), lung adenocarcinoma ( $\mathrm{Pu}$ et al., 2020), and diffuse large B-cell lymphoma (Yu J. et al., 2019). Non-small-cell lung cancer or renal cell carcinoma induced an enhancement of cell proliferation, migration, and invasion via the LRG1-mediated TGF- $\beta$ pathway (Chokchaichamnankit et al., 2019; Li et al., 2019; Hong et al., 2020).

\section{Part Five: LRG1 Involved in Eye Diseases}

LRG1 not only showed relevant mechanisms associated with diabetes but also diabetes-related eye diseases. Baseline plasma LRG1 was associated with proliferative diabetic retinopathy, suggesting that it might be a desirable biomarker to predict the late proliferative stage of diabetic retinopathy (Zhang et al., 2019). LRG1 levels in plasma and vitreous were increased in the individuals with proliferative diabetic retinopathy (Chen C. et al., 2019). LRG1 had applications for other eye diseases. Protein expression of five genes, serpina3n (serine protease inhibitor A3N), lcn2 (lipocalin-2), ackr1 (atypical chemokine receptor 1), LRG1, and lamc3 (laminin subunit gamma 3), were validated at the level of the inner blood retinal barrier cells (Lipski et al., 2020). The level of LRG1 obtained from eyes in patients with neovascular agerelated macular degeneration were increased, which indicated the target therapeutic therapy of anti-LRG1 monoclonal antibody (Mundo et al., 2021). LRG1 activated NADPH oxidase four to promote the epithelial mesenchymal transition of retinal pigment epithelium cells, which explored the potential mechanism for subretinal fibrosis in the basic experiment (Zhou et al., 2021).

\section{Part Six: LRG1 Involved in Nervous System Diseases}

There were many etiologies that could cause neurological diseases, including poisoning, genetic defects, nutritional disorders, immune damage, metabolic disorders, and 
endocrine disorders. There were relatively comprehensive clinical and basic studies on the function of LRG1 in stroke diseases. Serum level of LRG1 was identified as a potential indicator for the prediction of cardioembolic stroke, as well as pediatric spinal cord injury (Zhang M. et al., 2021; Ma et al., 2021). Apolipoprotein CII, LRG1, and C-reactive protein expression were significantly downregulated in poststroke depression relative to stroke subjects (Zhan et al., 2014). On fundamental researches, microglial M2 polarization was marked with chitinase 3-like protein one and LRG1 in bone marrow-resident monocytes induced by ischemia (Gregory et al., 2010). LRG1 might promote the cascade of angiogenesis via the modulation of TGF- $\beta 1$ pathway in middle cerebral artery occlusion rat. The glucose concentration affected LRG1 methylation in cortical slices and could modify neurodevelopmental outcomes (Chong et al., 2018) LRG1 promoted apoptosis and autophagy via the regulation of the TGF- $\beta$-smad1/5 signaling pathway by upregulating activin receptor-like kinase 1, which exacerbated ischemia reperfusion injury (Jin et al., 2019). Blockade of LRG1 attenuated angiogenesis by mediating its modulation of TGF- $\beta$ signaling (Wang et al., 2013).

So far, the etiology of many neurological diseases was unknown, and new biomarkers for nervous system diseases should be identified. A combination of positive tests such as LRG1 and tau protein could reliably predict the outcome in elderly patients with Idiopathic atmospheric hydrocephalus (Nakajima, Arai, and Miyajima 2010; Nakajima et al., 2011). An abonormal accumulation of LRG1 in brain of parkinson patients with subtypes of dementia and progressive supranuclear palsy was deemed to be a cause of neurodegeneration (Miyajima et al., 2013). Additionally, LRG1 shaped hippocampal circuits and establishes the assembly of tyrosine kinase receptor B, with LRG1 expanding the repertoire of responses to brain-derived neurotrophic factors during brain development (Alsina et al., 2016). LRG1 got more superior performance than interleukin-6 in the prediction for inflammatory diseases of the central nervous system (Chong et al., 2018). Cartier et al. (2018) Hippocampal LRG1 overexpression contributed to fewer synaptic vesicles and junctions, which led to memory impairment with increased age (Akiba et al., 2017). Three protein expression LRG1, secretoglobin family $3 \mathrm{~A}$ member 1 , and peptidoglycan recognition protein one were mainly associated with inflammation and apoptosis and they regulated the regeneration of nerves (Zheng et al., 2019). The perilipin 4, lipocalin-2, LRG1, forkhead Box F1, and cytotoxic T lymphocyte-associated protein two alpha genes were significantly upregulated in sevofluraneinduced Alzheimer's-related neuropathology in mice (Ge et al., 2019). LRG1 expression increased in resident astrocytes with age (Nakajima et al., 2012).

\section{Part Seven: LRG1 Involved in Cardiovascular Diseases}

LRG1 has promising application value in clinical diagnosis and prediction for congestive heart failure and cardiomyopathy (Liu M. et al., 2020). Omics results suggested that metabonomics was a promising new biomarker for cardiovascular diseases. LRG1 might be a potential serum biomarker for early onset myocardial infarction, while a combined biomarker signature that included BNP (plasma brain natriuretic peptide) would be a more accurate predictor of heart failure than BNP alone (Xuan et al., 2019). TLRG1 was the most prominent biomarker, among others, to predict the pathological progress of heart failure (Tonry et al., 2021). LRG1 was selected to distinguish persistent atrial fibrillation patients and control subjects (Cao et al., 2020). Predictive molecules of LRG1 and miRNAs engaged in pathological development of stable coronary artery disease progressing to acute myocardial infarction (Xiao et al., 2021). Proteomic study of serum exosomes from patients with kawasaki disease coronary aneurysm identified four proteins, TN, RBP4, LRG1, and APOA4 as the specific biomarkers (Xie XF. et al., 2019). Due to their great potential in the prediction of cardiovascular diseases, particular methods and mechanisms had yet to be investigated. Uncovering potential lncRNAs and mRNAs, including LRG1 was essential biomarkers from acute myocardial infarction aggravated to heart failure (Tonry et al., 2021; Wang et al., 2021). In terms of mechanism research, overexpressed miR-494 bound with LRG1 inactivated Wnt signaling pathway might promote fibroblasts and vascular endothelial cells proliferation in myocardial infarction ( $\mathrm{Su}$ et al., 2019). LRG1 or $\operatorname{PPAR} \beta / \delta$ represented a promising therapeutic strategy for the inhibition of pathological cardiac reshaping (Liu et al., 2019).

\section{Part Eight: LRG1 Involved in Immune Diseases}

The cause of the immune disease is complicated, and there is little cure for its problems. Generally, not only the initiator but also a series of inflammatory introduction systems activated on the basis of immunity could be investigated to determine the causes of rheumatoid arthritis. Plasma levels of LRG1 were relevant with disease activity of lupus nephritis (Yang Y. et al., 2020). Urine levels of LRG1, orosomucoid one ans two were positively associated with diseases of urinary system (Sun et al., 2020). LRG1 specially expressed in the acute phase of kawasaki disease rather than in the convalescence of Kawasaki disease (Kimura et al., 2017; Yanagimachi et al., 2021). The serum level of LRG1 could validly predict progression and prognosis of interstitial pneumonia with dermatomyositis (Ishida et al., 2020). Serum LRG1 levels were normalized in the inactive systemic juvenile idiopathic arthritis phase after treatment (Shimizu et al., 2019). During the treatment of interleukin- 6 receptor blockers, serum levels of LRG1 has good prediction ability for systemic juvenile idiopathic arthritis (Shimizu et al., 2017). Serum LRG exerted its superiority to mucosal healing in ulcerative colitis rather than C-reactive protein levels (Shinzaki et al., 2017). Serum LRG1 could also act as a useful biomarker to monitoring disease activity of inflammatory bowel disease during anti-TNF treatment (Shinzaki et al., 2021).

In basic research related to immunity diseases, interleukin-22 also promoted the expression of ERK1/2 (extracellular signal regulated kinase)-independent genes, such as LRG1, which were involved in inducing cell proliferation in intestinal epithelial cells (Moniruzzaman et al., 2019). PPAR $\beta / \delta$ regulated LRG1 in 
fibroblasts through TGF- $\beta 1$ could promote the pathological progression of skin diseases (Sng et al., 2018). Inhibition of TNF- $\alpha$ (tumor necrosis factor $\alpha$ ) and LRG1 by lenalidomide by induction of angiogenic cascade and recruitment of mesenchymal stem cells in subchondral bone could be a potential therapeutic approach for de novo bone formation (Wang et al., 2017b). LRG1 facilitated the activities of Th17 differentiation related arthritis diseases via upregulating interleukin-6 expression in Naive CD4 T cells (Urushima et al., 2017).

\section{Part Nine: LRG1 Involved in Infectious Diseases}

Infections could be distributed in any part of the body, which has always attracted attention from the public. There were significant differences in expression levels of LRG1 and $a-1$ antichymotrypsin between the healthy group and the leptospirosis group, but were no significant differences in the dengue control group (Fish-Low et al., 2020). A five protein panel of complement factor $\mathrm{H}$ related 5, LRG1, C-reactive protein, lipopolysaccharide binding protein, and serum amyloid A1 had specific predictive power in distinguishing tuberculosis and other respiratory diseases (Garay-Baquero et al., 2020). The ROC (receiver operating characteristic curve) identified nine transcriptomic genes, including LRG1, as potential new biomarkers for sepsis (Gong et al., 2020). Ten genes included LRG1 were differentially expressed in sepsis compared with nonsepsis blood (Lu et al., 2020) (Hashida et al., 2017). In the basic study of infectious diseases, LRG1 participated in FOS-like 1-regulated gene expression during lipopolysaccharide-induced human lung pulmonary endothelial cell angiogenesis (Nitkin et al., 2020). LRG1 repressed cellular signal-regulated kinase one activity by downregulating GTPase cell division cycle 42, and its downstream mitogen-activated protein kinase cascade diminished fungal virulence in a mouse model of Candida albicans infection (Chen T. et al., 2019).

LRG1 provided a novel biomarker for the evolution of cellular microbiology and infectious diseases. LRG1 stimulated combined with inflammatory cytokines served as a promising biomarker for infection of fetal hepatocytes (Kajimoto et al., 2020). Plasma proteomics of the kidney tissue obtained from newborn lippolysaccharide pigs showed elevated five protein levels involving LRG1, which were associated with activation of natural immunity (Muk et al., 2020). Circulating human mRNA and protein levels of LRG1 had good prediction ability for acute appendicitis in adults or children (Rainer et al., 2017; Kakar et al., 2021). Incorporated urinary biomarker model with LRG1, constant pain, right iliac fossa tenderness, and pain on percussion play the critical role in the prediction for appendicitis in children (Yap et al., 2019). However, there were also studies that showed that plasma levels of LRG1 were ineffective in the diagnosis of acute appendicitis in female patients accompanied by acute abdominal pain (Demirci et al., 2017). In addition, LRG1 and other five genes were found to be the key genes in steroidinduced femoral head necrosis. TNF- $\alpha$-induced LRG1 secretion could recruit MSCs to osteoarthritic subchondral bones via promoting vessel regeneration coupled with new bone formation (Verweyen et al., 2021; Yang et al., 2021).

\section{Part Ten: LRG1 Involved in Other Diseases}

LRG1 was an innovative biomarker for psoriasis, immunoglobulin G4-related disease, and fibromyalgia (Nakajima et al., 2017; Hsu et al., 2021; Kawanami et al., 2021). LRG1 combined with other five proteins could act as the biomarkers well connected with middle or end coronary events in atherosclerotic patients with any genetic subtypes (Bos et al., 2017). Additionally, in some basic research experiments, LRG1 might uncouple mechanical forces necessary for angiogenesis, which underline the potential therapeutic methods for fibro-proliferative diseases (Gao et al., 2019). Mesenchymal stem-derived extracellular vesicles microrNA129-5p could attenuate the degeneration of intervertebral disc mediated by LRG1 inactivated P38 MAPK signaling pathway (Yang et al., 2021). Knockdown of LRG1 inhibited corneal angiogenesis and lymphangiogenesis in corneal alkali burn mice by modulating the protein expression of vascular endothelial growth factor A, B, C, D (Song et al., 2020). LRG1 stimulated neutrophil infiltration by regulating IL-6/Stat3 (signal transducer and activator of transcription 3) to facilitate the corneal fibrosis responses (Yu, Yang, et al., 2021).

\section{DISCUSSION}

At present, many proteins with leucine-rich repeat structures had been found in the nervous system, other systems, and body fluids, and research on their functions was still a hot research direction in the future. In recent years, an increasing number of studies have found that LRG1 could exert its effects by promoting the TGF- $\beta$ signaling pathway and then affecting downstream biological effects through smad-dependent and non-smaddependent pathways. In mammals, TGF- $\beta$ mainly was identified with three subtypes: TGF- $\beta 1$, TGF- $\beta 2$, and TGF- $\beta 3$, among which TGF- $\beta 1$ exerted a large portion of its biological effects.

During this process, LRG1 played an important role in the TGF- $\beta 1$ pathway: 1) (Figure 2) Endoglin was proposed as a key regulatory molecule in promoting signalling through the ALK (activin receptor-like kinase) pathway. In the presence of coreceptor endoglin, LRG1 activated the TGF angiogenic switch binding to the accessory receptor endoglin by in the presence of TGF- $\beta 1$. The activation of TGF- $\beta 1$ bound with TGF-beta-receptor-II, which predominantly recruited the endothelial TGF-beta-receptor-I and ALK to the highly conserved proximal membrane region to undergo phosphorylation. Then the phosphorylation of TGF-betareceptor-I/ALK stimulated Smad receptor family to form the hetero-oligomic complex and transport to the nucleus, and then interacted with transcriptional coactivators and co-inhibitors, such as P300 and cAMP-response element binding protein to mediate the biological effects of TGF- $\beta 1$. The complex of LRG1TGF-beta-receptor-I-endoglin-ALK1 activated the downstream smad1/5/8 pathway and promoted endothelial cell migration and 
angiogenesis (Wang et al., 2013); 2) ALK1 and ALK5 were the both direct receptors of TGF- $\beta 1$, through antagonizing, supplementing, and restricting each other to maintain body balance. Inparticular, the balance between the ALK5 and ALK1 signalling pathways is considered to becentral in determining the angiogenic switch. Under the influence of different factors, they showed different tendencies towards TGF- $\beta 1$. In the absence of coreceptor endoglin, LRG1 would combine with TGF-beta-receptor-I/ALK5 to form a complex of LRG1-TGF-beta-receptor-I/ALK5, which stimulated the downstream smad2/3 pathway and promoted the deposition of extracellular cytoplasm. It regulated the differentiation of $\mathrm{T}$ cells and promoted the synthesis of endothelial nitric oxide synthase (Wang et al., 2013). 3) In addition to this, LRG1-induced TGF- $\beta$ pathway could activate upstream signaling molecules RhoA, Ras to activate MKKs (MAP kinase), MEKs (MAPK/ERK kinase), mitogen-activated protein kinase (JNK/SPAK, p38, ERK1/2), TAK1 (TGF-Beta Activated kinase), TAB1 (TAK1 Binding Protein), XIAP (Xenopus Inhibitor of Apoptosis), HPK1 (Haematopoietic Progenitor Kinase-1), PI3K (phosphatidylinositol-3-kinase), and AKT kinase, etc (Moustakas et al., 2002; Travis and Sheppard, 2014; Costanza et al., 2017; Liu C. et al., 2020).

\section{CONCLUSION}

In conclusion, it is particularly important to explore new therapeutic drugs and schemes to reduce the economic burden

\section{REFERENCES}

Akiba, C., Nakajima, M., Miyajima, M., Ogino, I., Miura, M., Inoue, R., et al. (2017). Leucine-rich a2-glycoprotein Overexpression in the Brain Contributes to Memory Impairment. Neurobiol. Aging 60, 11-19. doi:10.1016/ j.neurobiolaging.2017.08.014

Alsina, F. C., Hita, F. J., Fontanet, P. A., Irala, D., Hedman, H., Ledda, F., et al. (2016). Lrig1 Is a Cell-Intrinsic Modulator of Hippocampal Dendrite Complexity and BDNF Signaling. EMBO Rep. 17 (4), 601-616. doi:10.15252/embr.201541218

Ban, Z., He, J., Tang, Z., Zhang, L., and Xu, Z. (2019). LRG-1 Enhances the Migration of Thyroid Carcinoma Cells through Promotion of the EpithelialMesenchymal Transition by Activating MAPK/p38 Signaling. Oncol. Rep. 41 (6), 3270-3280. doi:10.3892/or.2019.7123

Bos, S., Phillips, M., Watts, G. F., Verhoeven, A. J. M., Sijbrands, E. J. G., and Ward, N. C. (2017). Novel Protein Biomarkers Associated with Coronary Artery Disease in Statin-Treated Patients with Familial Hypercholesterolemia. J. Clin. Lipidol. 11 (3), 682-693. doi:10.1016/j.jacl.2017.03.014

Cao, H., Zhu, X., Chen, X., Yang, Y., Zhou, Q., Xu, W., et al. (2020). Quantitative Proteomic Analysis to Identify Differentially Expressed Proteins in the Persistent Atrial Fibrillation Using TMT Coupled with nano-LC-MS/MS. Am. J. Transl Res. 12 (9), 5032-5047.

Cartier, J., Piyasena, C., Sparrow, S. A., Boardman, J. P., and Drake, A. J. (2018). Alterations in Glucose Concentrations Affect DNA Methylation at Lrg1 in an Ex Vivo Rat Cortical Slice Model of Preterm Brain Injury. Eur. J. Neurosci. 47 (5), 380-387. doi:10.1111/ejn.13825

Chang, S. C., Lin, W. L., Chang, Y. F., Lee, C. T., Wu, J. S., Hsu, P. H., et al. (2019). Glycoproteomic Identification of Novel Plasma Biomarkers for Oral Cancer. J. Food Drug Anal. 27 (2), 483-493. doi:10.1016/ j.jfda.2018.12.008 of patients and the development of diseases. LRG1 was a newly discovered important upstream signaling molecule of TGF- $\beta$ that affects various pathological processes through the TGF- $\beta$ signaling pathway. Although research on LRG1 in the occurrence and development of diseases was still in its infancy, clinical evidence was still scarce, mainly concentrated on proteomic detection and basic experimental reports. However, the monoclonal antibody magacizumab specifically targeting LRG1 was currently in phase I and II clinical trials (Radgonde et al., 2018). We could reasonably predict that LRG1 might serve as a novel target for treatment of disease disorders.

\section{AUTHOR CONTRIBUTIONS}

All authors listed have made a substantial, direct, and intellectual contribution to the work and approved it for publication.

\section{FUNDING}

This work was supported by the Foundation Project: National Natural Science Foundation of China (No: 82100417, 81760094); The Foundation of Jiangxi Provincial Department of Science and Technology Youth Key Project (No. 20202ACBL206001, 20212BAB206022); Youth Project of Jiangxi Provincial Department of Education (No: GJJ200217). All funding bodies had no role in the design of the study and collection, analysis, and interpretation of the data or in writing the manuscript.

Chen, C., Chen, X., Huang, H., Han, C., Qu, Y., Jin, H., et al. (2019). Elevated Plasma and Vitreous Levels of Leucine-Rich-A2-Glycoprotein Are Associated with Diabetic Retinopathy Progression. Acta Ophthalmol. 97 (3), 260-264. doi:10.1111/aos.13633

Chen, T., Wagner, A. S., Tams, R. N., Eyer, J. E., Kauffman, S. J., Gann, E. R., et al. (2019). Lrg1 Regulates $\beta$ (1,3)-Glucan Masking in Candida Albicans through the Cek1 MAP Kinase Pathway. mBio 10 (5), e01767-19. doi:10.1128/ mBio.01767-19

Chen, W., Zheng, R., Baade, P. D., Zhang, S., Zeng, H., Bray, F., et al. (2016). Cancer Statistics in China, 2015. CA Cancer J. Clin. 66 (2), 115-132. doi:10.3322/ caac. 21338

Choi, Y. J., Yoon, W., Lee, A., Han, Y., Byun, Y., Kang, J. S., et al. (2021). Diagnostic Model for Pancreatic Cancer Using a Multi-Biomarker Panel. Ann. Surg. Treat. Res. 100 (3), 144-153. doi:10.4174/astr.2021.100.3.144

Chokchaichamnankit, D., Watcharatanyatip, K., Subhasitanont, P., Weeraphan, C., Keeratichamroen, S., Sritana, N., et al. (2019). Urinary Biomarkers for the Diagnosis of Cervical Cancer by Quantitative Labelfree Mass Spectrometry Analysis. Oncol. Lett. 17 (6), 5453-5468. doi:10.3892/ol.2019.10227

Chong, P. F., Sakai, Y., Torisu, H., Tanaka, T., Furuno, K., Mizuno, Y., et al. (2018). Leucine-rich Alpha-2 Glycoprotein in the Cerebrospinal Fluid Is a Potential Inflammatory Biomarker for Meningitis. J. Neurol. Sci. 392, 51-55. doi:10.1016/ j.jns.2018.07.006

Costanza, B., Umelo, I. A., Bellier, J., Castronovo, V., and Turtoi, A. (2017). Stromal Modulators of TGF- $\beta$ in Cancer. J. Clin. Med. 6 (1), piiE7. doi:10.3390/ jcm6010007

Demirci, O. L., Cevik, Y., Corbacioglu, S. K., and Taner, A. (2017). Value of Leucine-Rich Alpha-2-Glycoprotein-1 (LRG-1) on Diagnosis of Acute Appendicitis in Female Patients with Right Lower-Quadrant Abdominal Pain. J. Pak Med. Assoc. 67 (9), 1383-1386. doi:10.3969/J.issn.16713141.2021.07.112 
Fahrmann, J. F., Bantis, L. E., Capello, M., Scelo, G., Dennison, J. B., Patel, N., et al. (2019). A Plasma-Derived Protein-Metabolite Multiplexed Panel for EarlyStage Pancreatic Cancer. J. Natl. Cancer Inst. 111 (4), 372-379. doi:10.1093/ jnci/djy126

Fahrmann, J. F., Schmidt, C. M., Mao, X., Irajizad, E., Loftus, M., Zhang, J., et al. (2021). Lead-time Trajectory of CA19-9 as an Anchor Marker for Pancreatic Cancer Early Detection. Gastroenterology 160 (4), 1373-e6. doi:10.1053/ j.gastro.2020.11.052

Fan, M., Li, C., He, P., Fu, Y., Li, M., and Zhao, X. (2019). Knockdown of Long Noncoding RNA-Taurine-Upregulated Gene 1 Inhibits Tumor Angiogenesis in Ovarian Cancer by Regulating Leucine-Rich $\alpha$-2-glycoprotein-1. Anticancer Drugs 30 (6), 562-570. doi:10.1097/CAD.0000000000000734

Fish-Low, C. Y., Than, L. T. L., Ling, K. H., Lin, Q., and Sekawi, Z. (2020). Plasma Proteome Profiling Reveals Differentially Expressed LipopolysaccharideBinding Protein Among Leptospirosis Patients. J. Microbiol. Immunol. Infect. 53 (1), 157-162. doi:10.1016/j.jmii.2018.12.015

Fouda, M. S., Aljarwani, R. M., Aboul-Enein, K., and Omran, M. M. (2021). Diagnostic Performances of Leucine-Rich $\alpha$-2-glycoprotein 1 and Stem Cell Factor for Diagnosis and Follow-Up of Colorectal Cancer. J. Genet. Eng. Biotechnol. 19 (1), 17. doi:10.1186/s43141-021-00116-3

Fu, J., Wei, C., Zhang, W., Schlondorff, D., Wu, J., Cai, M., et al. (2018). Gene Expression Profiles of Glomerular Endothelial Cells Support Their Role in the Glomerulopathy of Diabetic Mice. Kidney Int. 94 (2), 326-345. doi:10.1016/ j.kint.2018.02.028

Fujimoto, M., Matsumoto, T., Serada, S., Tsujimura, Y., Hashimoto, S., Yasutomi, Y., et al. (2020). Leucine-rich Alpha 2 Glycoprotein Is a New Marker for Active Disease of Tuberculosis. Sci. Rep. 10 (1), 3384. doi:10.1038/s41598-020-60450-3

Fukamachi, K., Hagiwara, Y., Futakuchi, M., Alexander, D. B., Tsuda, H., and Suzui, M. (2019). Evaluation of a Biomarker for the Diagnosis of Pancreas Cancer Using an Animal Model. J. Toxicol. Pathol. 32 (3), 135-141. doi:10.1293/tox.2018-0062

Furuta, T., Sugita, Y., Komaki, S., Ohshima, K., Morioka, M., Uchida, Y., et al. (2020). The Multipotential of Leucine-Rich $\alpha-2$ Glycoprotein 1 as a Clinicopathological Biomarker of Glioblastoma. J. Neuropathol. Exp. Neurol. 79 (8), 873-879. doi:10.1093/jnen/nlaa058

Gao, Y., Zhou, J., Xie, Z., Wang, J., Ho, C. K., Zhang, Y., et al. (2019). Mechanical Strain Promotes Skin Fibrosis through LRG-1 Induction Mediated by ELK1 and ERK Signalling. Commun. Biol. 2, 359. doi:10.1038/s42003-019-0600-6

Garay-Baquero, D. J., White, C. H., Walker, N. F., Tebruegge, M., Schiff, H. F., Ugarte-Gil, C., et al. (2020). Comprehensive Plasma Proteomic Profiling Reveals Biomarkers for Active Tuberculosis. JCI Insight 5 (18), e137427. doi:10.1172/jci.insight.137427

Ge, X., Zhang, Y., Zuo, Y., Israr, M., Li, B., Yu, P., et al. (2019). Transcriptomic Analysis Reveals the Molecular Mechanism of Alzheimer-Related Neuropathology Induced by Sevoflurane in Mice. J. Cel Biochem 120 (10), 17555-17565. doi:10.1002/jcb.29020

Gong, F. C., Ji, R., Wang, Y. M., Yang, Z. T., Chen, Y., Mao, E. Q., et al. (2020). Identification of Potential Biomarkers and Immune Features of Sepsis Using Bioinformatics Analysis. Mediators Inflamm. 2020, 3432587. doi:10.1155/2020/ 3432587

Gregory, A. D., Capoccia, B. J., Woloszynek, J. R., and Link, D. C. (2010). Systemic Levels of G-CSF and Interleukin-6 Determine the Angiogenic Potential of Bone Marrow Resident Monocytes. J. Leukoc. Biol. 88 (1), 123-131. doi:10.1189/ jlb.0709499

Gu, Z., Xie, D., Huang, C., Ding, R., Zhang, R., Li, Q., et al. (2020). MicroRNA-497 Elevation or LRG1 Knockdown Promotes Osteoblast Proliferation and Collagen Synthesis in Osteoporosis via TGF- $\beta 1 /$ Smads Signalling Pathway. J. Cel Mol Med 24 (21), 12619-12632. doi:10.1111/jcmm.15826

Gurung, R. L., Dorajoo, R., Yiamunaa, M., Pek, S. L. T., Wang, J., Wang, L., et al. (2021). Association of Genetic Variants for Plasma LRG1 with Rapid Decline in Kidney Function in Patients with Type 2 Diabetes. J. Clin. Endocrinol. Metab. 106 (8), 2384-2394. doi:10.1210/clinem/dgab268

Haku, S., Wakui, H., Azushima, K., Haruhara, K., Kinguchi, S., Ohki, K., et al. (2018). Early Enhanced Leucine-Rich $\alpha$-2-Glycoprotein-1 Expression in Glomerular Endothelial Cells of Type 2 Diabetic Nephropathy Model Mice. Biomed. Res. Int. 2018, 2817045. doi:10.1155/2018/2817045

Hao, L., Xie, H., Zhang, B., Chen, D., Wang, S., Zhang, H., et al. (2016). LRG1 Downregulation in Allergic Airway Disorders and its Expression in Peripheral
Blood and Tissue Cells. J. Transl Med. 14 (1), 202. doi:10.1186/s12967-0160929-2

Hao, L. J., Zheng, W. J., Wang, S. F., Zheng, Y., He, S. H., and Zhang, B. (2016). [Expression of LRG-1 in Clinical Specimens and Tca8113 Cell Line of Tongue Carcinoma]. Nan Fang Yi Ke Da Xue Xue Bao 36 (3), 297-302. doi:10.1186/ s12967-016-0929-2

Harlid, S., Gunter, M. J., and Van Guelpen, B. (2021). Risk-Predictive and Diagnostic Biomarkers for Colorectal Cancer; a Systematic Review of Studies Using Pre-diagnostic Blood Samples Collected in Prospective Cohorts and Screening Settings. Cancers (Basel) 13 (17), 4406. doi:10.3390/ cancers 13174406

Hashida, T., Nakada, T. A., Satoh, M., Tomita, K., Kawaguchi, R., Nomura, F., et al. (2017). Proteome Analysis of Hemofilter Adsorbates to Identify Novel Substances of Sepsis: a Pilot Study. J. Artif. Organs 20 (2), 132-137. doi:10.1007/s10047-016-0936-3

Haupt, H., and Baudner, S. (1977). [Isolation and Characterization of an Unknown, Leucine-Rich 3.1-S-Alpha2-Glycoprotein from Human Serum (Author's Transl)], Leucine-rich 3.1-S-alpha2-glycoprotein from Human Serum. Hoppe Seylers Z. Physiol. Chem. 358 (6), 639-646. doi:10.1515/bchm2.1977.358.1.639

Hisata, S., Racanelli, A. C., Kermani, P., Schreiner, R., Houghton, S., Palikuqi, B., et al. (2021). Reversal of Emphysema by Restoration of Pulmonary Endothelial Cells. J. Exp. Med. 218 (8), e20200938. doi:10.1084/jem.20200938

Honda, H., Fujimoto, M., Miyamoto, S., Ishikawa, N., Serada, S., Hattori, N., et al. (2016). Sputum Leucine-Rich Alpha-2 Glycoprotein as a Marker of Airway Inflammation in Asthma. PLoS One 11 (9), e0162672. doi:10.1371/ journal.pone. 0162672

Honda, H., Fujimoto, M., Serada, S., Urushima, H., Mishima, T., Lee, H., et al. (2017). Leucine-rich $\alpha-2$ Glycoprotein Promotes Lung Fibrosis by Modulating TGF- $\beta$ Signaling in Fibroblasts. Physiol. Rep. 5 (24), e13556. doi:10.14814/ phy2.13556

Hong, Q., Wang, S., Liu, S., Chen, X., and Cai, G. (2020). LRG1 May Accelerate the Progression of ccRCC via the TGF- $\beta$ Pathway. Biomed. Res. Int. 2020, 1285068. doi:10.1155/2020/1285068

Hong, Q., Zhang, L., Fu, J., Verghese, D. A., Chauhan, K., Nadkarni, G. N., et al. (2019). LRG1 Promotes Diabetic Kidney Disease Progression by Enhancing TGF- $\beta$-Induced Angiogenesis. J. Am. Soc. Nephrol. 30 (4), 546-562. doi:10.1681/ASN.2018060599

Hsu, W. H., Han, D. S., Ku, W. C., Chao, Y. M., Chen, C. C., and Lin, Y. L. (2021). Metabolomic and Proteomic Characterization of Sng and Pain Phenotypes in Fibromyalgia. Eur. J. Pain. doi:10.1002/ejp.1871

Iqbal, Z., Fachim, H. A., Gibson, J. M., Baricevic-Jones, I., Campbell, A. E., Geary, B., et al. (2021). Changes in the Proteome Profile of People Achieving Remission of Type 2 Diabetes after Bariatric Surgery. J. Clin. Med. 10 (16), 3659. doi: $10.3390 / \mathrm{jcm} 10163659$

Ishida, T., Kotani, T., Serada, S., Fujimoto, M., Takeuchi, T., Makino, S., et al. (2020). Correlation of Increased Serum Leucine-Rich a2-glycoprotein Levels with Disease Prognosis, Progression, and Activity of Interstitial Pneumonia in Patients with Dermatomyositis: A Retrospective Study. PLoS One 15 (6), e0234090. doi:10.1371/journal.pone. 0234090

Jemmerson, R., Staskus, K., Higgins, L., Conklin, K., and Kelekar, A. (2021). Intracellular Leucine-Rich Alpha-2-Glycoprotein-1 Competes with Apaf-1 for Binding Cytochrome C in Protecting MCF-7 Breast Cancer Cells from Apoptosis. Apoptosis 26 (1-2), 71-82. doi:10.1007/s10495-020-01647-9

Jiang, W., Ma, T., Zhang, C., Tang, X., Xu, Q., Meng, X., et al. (2020). Identification of Urinary Candidate Biomarkers of Cisplatin-Induced Nephrotoxicity in Patients with Carcinoma. J. Proteomics 210, 103533. doi:10.1016/ j.jprot.2019.103533

Jin, J., Sun, H., Liu, D., Wang, H., Liu, Q., Chen, H., et al. (2019). LRG1 Promotes Apoptosis and Autophagy through the TGF $\beta$-Smad1/5 Signaling Pathway to Exacerbate Ischemia/Reperfusion Injury. Neuroscience 413, 123-134. doi:10.1016/j.neuroscience.2019.06.008

Jin, Z., Kobayashi, S., Gotoh, K., Takahashi, T., Eguchi, H., Naka, T., et al. (2020). The Prognostic Impact of Leucine-Rich $\alpha$-2-Glycoprotein-1 in Cholangiocarcinoma and its Association with the IL-6/TGF- $\beta 1$ Axis. J. Surg. Res. 252, 147-155. doi:10.1016/j.jss.2020.03.018

Kajimoto, E., Endo, M., Fujimoto, M., Matsuzaki, S., Fujii, M., Yagi, K., et al. (2020). Evaluation of Leucine-Rich Alpha-2 Glycoprotein as a Biomarker of Fetal Infection. PLoS One 15 (11), e0242076. doi:10.1371/journal.pone.0242076 
Kakar, M., Berezovska, M. M., Broks, R., Asare, L., Delorme, M., Crouzen, E., et al. (2021). Serum and Urine Biomarker Leucine-Rich Alpha-2 Glycoprotein 1 Differentiates Pediatric Acute Complicated and Uncomplicated Appendicitis. Diagnostics (Basel) 11 (5). doi:10.3390/ diagnostics 11050860

Kamalipooya, S., Zarezadeh, R., Latifi, Z., Nouri, M., Fattahi, A., and Salemi, Z. (2021). Serum Transforming Growth Factor $\beta$ and Leucine-Rich $\alpha-2$ glycoprotein 1 as Potential Biomarkers for Diagnosis of Uterine Leiomyomas. J. Gynecol. Obstet. Hum. Reprod. 50 (3), 102037. doi:10.1016/ j.jogoh.2020.102037

Kawanami, T., Kawanami-Iwao, H., Takata, T., Ishigaki, Y., Tomosugi, N., Takegami, T., et al. (2021). Comprehensive Analysis of Protein-Expression Changes Specific to Immunoglobulin G4-Related Disease. Clin. Chim. Acta 523, 45-57. doi:10.1016/j.cca.2021.08.025

Kimura, Y., Yanagimachi, M., Ino, Y., Aketagawa, M., Matsuo, M., Okayama, A., et al. (2017). Identification of Candidate Diagnostic Serum Biomarkers for Kawasaki Disease Using Proteomic Analysis. Sci. Rep. 7, 43732. doi:10.1038/ srep 43732

Komor, M. A., Bosch, L. J., Coupé, V. M., Rausch, C., Pham, T. V., Piersma, S. R., et al. (2020). Proteins in Stool as Biomarkers for Non-invasive Detection of Colorectal Adenomas with High Risk of Progression. J. Pathol. 250 (3), 288-298. doi:10.1002/path.5369

Kopylov, A. T., Stepanov, A. A., Malsagova, K. A., Soni, D., Kushlinsky, N. E., Enikeev, D. V., et al. (2020). Revelation of Proteomic Indicators for Colorectal Cancer in Initial Stages of Development. Molecules 25 (3), 619. doi:10.3390/ molecules25030619

Lee, D. H., Yoon, W., Lee, A., Han, Y., Byun, Y., Kang, J. S., et al. (2021). Multibiomarker Panel Prediction Model for Diagnosis of Pancreatic Cancer. J. Hepatobiliary Pancreat. Sci. doi:10.14701/ahbps.bp-best-op-2

Lee, H., Fujimoto, M., Ohkawara, T., Honda, H., Serada, S., Terada, Y., et al. (2018). Leucine Rich $a-2$ Glycoprotein Is a Potential Urinary Biomarker for Renal Tubular Injury. Biochem. Biophys. Res. Commun. 498 (4), 1045-1051. doi:10.1016/j.bbrc.2018.03.111

Lee, H. G., Kim, S. J., Park, I. J., Hong, S. M., Lim, S. B., Lee, J. B., et al. (2019). Effect of Responsiveness of Lymph Nodes to Preoperative Chemoradiotherapy in Patients with Rectal Cancer on Prognosis after Radical Resection. Clin. Colorectal Cancer 18 (2), e191-e9. doi:10.1016/j.clcc.2019.03.001

Li, W., Wang, X., Cheng, J., Li, J., Wang, Q., Zhou, Q., et al. (2020). Leucine-rich a-2-glycoprotein-1 Promotes Diabetic Corneal Epithelial Wound Healing and Nerve Regeneration via Regulation of Matrix Metalloproteinases. Exp. Eye Res. 196, 108060. doi:10.1016/j.exer.2020.108060

Li, Z., Zeng, C., Nong, Q., Long, F., Liu, J., Mu, Z., et al. (2019). Exosomal LeucineRich-Alpha2-Glycoprotein 1 Derived from Non-small-cell Lung Cancer Cells Promotes Angiogenesis via TGF- $\beta$ Signal Pathway. Mol. Ther. Oncolytics 14, 313-322. doi:10.1016/j.omto.2019.08.001

Lipski, D. A., Foucart, V., Dewispelaere, R., Caspers, L. E., Defrance, M., Bruyns, C., et al. (2020). Retinal Endothelial Cell Phenotypic Modifications during Experimental Autoimmune Uveitis: a Transcriptomic Approach. BMC Ophthalmol. 20 (1), 106. doi:10.1186/s12886-020-1333-5

Liu, C., Lim, S. T., Teo, M. H. Y., Tan, M. S. Y., Kulkarni, M. D., Qiu, B., et al. (2019). Collaborative Regulation of LRG1 by TGF-B1 and PPAR-B/ $\delta$ Modulates Chronic Pressure Overload-Induced Cardiac Fibrosis. Circ. Heart Fail. 12 (12), e005962. doi:10.1161/ CIRCHEARTFAILURE. 119.005962

Liu, C., Teo, M. H. Y., Pek, S. L. T., Wu, X., Leong, M. L., Tay, H. M., et al. (2020). A Multifunctional Role of Leucine-Rich a-2-Glycoprotein 1 in Cutaneous Wound Healing under Normal and Diabetic Conditions. Diabetes 69 (11), 2467-2480. doi: $10.2337 / \mathrm{db} 20-0585$

Liu, J.-J., Pek, S. L. T., Liu, S., Wang, J., Lee, J., Ang, K., et al. (2021). Association of Plasma Leucine-Rich Alpha-2 Glycoprotein 1 (LRG1) with All-Cause and Cause-specific Mortality in Individuals with Type 2 Diabetes. Clin. Chem. 67, 1640-1649. doi:10.1093/clinchem/hvab172

Liu, J. J., Pek, S. L. T., Ang, K., Tavintharan, S., and Lim, S. C. (2017). Plasma Leucine-Rich $\alpha$-2-Glycoprotein 1 Predicts Rapid eGFR Decline and Albuminuria Progression in Type 2 Diabetes Mellitus. J. Clin. Endocrinol. Metab. 102 (10), 3683-3691. doi:10.1210/jc.2017-00930

Liu, J. J., Pek, S. L. T., Wang, J., Liu, S., Ang, K., Shao, Y. M., et al. (2021). Association of Plasma Leucine-Rich a-2 Glycoprotein 1, a Modulator of
Transforming Growth Factor- $\beta$ Signaling Pathway, with Incident Heart Failure in Individuals with Type 2 Diabetes. Diabetes Care 44 (2), 571-577. doi: $10.2337 / \mathrm{dc} 20-2065$

Liu, M., Köster, L. S., Fosgate, G. T., Chadwick, C. C., Sanz-González, Í., Eckersall, P. D., et al. (2020). Cardiovascular-renal axis Disorder and Acute-phase Proteins in Cats with Congestive Heart Failure Caused by Primary Cardiomyopathy. J. Vet. Intern. Med. 34 (3), 1078-1090. doi:10.1111/ jvim. 15757

Lou, T., Ke, K., Zhang, L., Miao, C., and Liu, Y. (2020). LncRNA PART1 Facilitates the Malignant Progression of Colorectal Cancer via miR-150-5p/LRG1 axis. J. Cel Biochem 121 (10), 4271-4281. doi:10.1002/jcb.29635

Low, S., Pek, S., Moh, A., Khin, C. Y. A., Lim, C. L., Ang, S. F., et al. (2021). Low Muscle Mass Is Associated with Progression of Chronic Kidney Disease and Albuminuria - an 8-year Longitudinal Study in Asians with Type 2 Diabetes. Diabetes Res. Clin. Pract. 174, 108777. doi:10.1016/j.diabres.2021.108777

Lu, J., Li, Q., Wu, Z., Zhong, Z., Ji, P., Li, H., et al. (2020). Two Gene Set Variation Indexes as Potential Diagnostic Tool for Sepsis. Am. J. Transl Res. 12 (6), 2749-2759.

Luan, L., Hu, Q., Wang, Y., Lu, L., and Ling, J. (2021). Knockdown of lncRNA NEAT1 Expression Inhibits Cell Migration, Invasion and EMT by Regulating the miR-24-3p/LRG1 axis in Retinoblastoma Cells. Exp. Ther. Med. 21 (4), 367. doi:10.3892/etm.2021.9798

Lynch, J., Fay, J., Meehan, M., Bryan, K., Watters, K. M., Murphy, D. M., et al. (2012). MiRNA-335 Suppresses Neuroblastoma Cell Invasiveness by Direct Targeting of Multiple Genes from the Non-canonical TGF- $\beta$ Signalling Pathway. Carcinogenesis 33 (5), 976-985. doi:10.1093/carcin/ bgs114

Ma, H., Lu, F., Guo, Y., Shen, Z., and Chen, Y. (2021). The Prognostic Value of Leucine-Rich $\alpha 2$ Glycoprotein 1 in Pediatric Spinal Cord Injury. Biomed. Res. Int. 2021, 7365204. doi:10.1155/2021/7365204

Majek, P., Pecankova, K., Cermak, J., and Dyr, J. E. (2015). Plasma Protein Biomarker Candidates for Myelodysplastic Syndrome Subgroups. Biomed. Res. Int. 2015, 209745. doi:10.1155/2015/209745

Masood, A., Benabdelkamel, H., Ekhzaimy, A. A., and Alfadda, A. A. (2020). Plasma-Based Proteomics Profiling of Patients with Hyperthyroidism after Antithyroid Treatment. Molecules 25 (12), 2831. doi:10.3390/ molecules 25122831

Miyajima, M., Nakajima, M., Motoi, Y., Moriya, M., Sugano, H., Ogino, I., et al. (2013). Leucine-rich a2-glycoprotein Is a Novel Biomarker of Neurodegenerative Disease in Human Cerebrospinal Fluid and Causes Neurodegeneration in Mouse Cerebral Cortex. PLoS One 8 (9), e74453. doi:10.1371/journal.pone.0074453

Miyauchi, E., Furuta, T., Ohtsuki, S., Tachikawa, M., Uchida, Y., Sabit, H., et al. (2018). Identification of Blood Biomarkers in Glioblastoma by SWATH Mass Spectrometry and Quantitative Targeted Absolute Proteomics. PLoS One 13 (3), e0193799. doi:10.1371/journal.pone.0193799

Mohamad Hanif, E. A. (2019). Dysregulation of Non-histone Molecule miR205 and LRG1 post-transcriptional De-regulation by SETD1A in Triple Negative Breast Cancer. Mol. Biol. Rep. 46 (6), 6617-6624. doi:10.1007/s11033-01905079-w

Moniruzzaman, M., Wang, R., Jeet, V., McGuckin, M. A., and Hasnain, S. Z. (2019). Interleukin (IL)-22 from IL-20 Subfamily of Cytokines Induces Colonic Epithelial Cell Proliferation Predominantly through ERK1/2 Pathway. Int. J. Mol. Sci. 20 (14), 3468. doi:10.3390/ijms20143468

Moustakas, A., Pardali, K., Gaal, A., and Heldin, C. H. (2002). Mechanisms of TGFBeta Signaling in Regulation of Cell Growth and Differentiation. Immunol. Lett. 82 (1-2), 85-91. doi:10.1016/s0165-2478(02)00023-8

Muk, T., Jiang, P. P., Stensballe, A., Skovgaard, K., Sangild, P. T., and Nguyen, D. N. (2020). Prenatal Endotoxin Exposure Induces Fetal and Neonatal Renal Inflammation via Innate and Th1 Immune Activation in Preterm Pigs. Front. Immunol. 11, 565484. doi:10.3389/fimmu.2020.565484

Mundo, L., Tosi, G. M., Lazzi, S., Pertile, G., Parolini, B., Neri, G., et al. (2021). LRG1 Expression Is Elevated in the Eyes of Patients with Neovascular AgeRelated Macular Degeneration. Int. J. Mol. Sci. 22 (16), 8879. doi:10.3390/ ijms 22168879

Nakajima, H., Serada, S., Fujimoto, M., Naka, T., and Sano, S. (2017). Leucine-rich a-2 Glycoprotein Is an Innovative Biomarker for Psoriasis. J. Dermatol. Sci. 86 (2), 170-174. doi:10.1016/j.jdermsci.2017.01.008 
Nakajima, M., Arai, H., and Miyajima, M. (2010). [Diagnostic Value of CSF Biomarker Profile in Idiopathic normal Pressure Hydrocephalus; Leucine-Rich a-2-glycoprotein Is a Potential Biological Marker]. Rinsho Shinkeigaku 50 (11), 973-976. doi:10.5692/clinicalneurol.50.973

Nakajima, M., Miyajima, M., Ogino, I., Watanabe, M., Hagiwara, Y., Segawa, T., et al. (2012). Brain Localization of Leucine-Rich a2-glycoprotein and its Role. Acta Neurochir Suppl. 113, 97-101. doi:10.1007/978-3-7091-0923-6_20

Nakajima, M., Miyajima, M., Ogino, I., Watanabe, M., Miyata, H., Karagiozov, K. L., et al. (2011). Leucine-rich $\alpha$-2-glycoprotein Is a Marker for Idiopathic normal Pressure Hydrocephalus. Acta Neurochir (Wien) 153 (6), 1339-1346; discussion 46. doi:10.1007/s00701-011-0963-z

Nambu, M., Masuda, T., Ito, S., Kato, K., Kojima, T., Daiko, H., et al. (2019). Leucine-Rich Alpha-2-Glycoprotein 1 in Serum Is a Possible Biomarker to Predict Response to Preoperative Chemoradiotherapy for Esophageal Cancer. Biol. Pharm. Bull. 42 (10), 1766-1771. doi:10.1248/bpb.b19-00395

Nitkin, C. R., Xia, S., Menden, H., Yu, W., Xiong, M., Heruth, D. P., et al. (2020). FOSL1 Is a Novel Mediator of Endotoxin/lipopolysaccharide-Induced Pulmonary Angiogenic Signaling. Sci. Rep. 10 (1), 13143. doi:10.1038/ s41598-020-69735-z

Pek, S. L. T., Cheng, A. K. S., Lin, M. X., Wong, M. S., Chan, E. Z. L., Moh, A. M. C., et al. (2018). Association of Circulating Proinflammatory Marker, LeucineRich-A2-Glycoprotein (LRG1), Following Metabolic/bariatric Surgery. Diabetes Metab. Res. Rev. 34 (7), e3029. doi:10.1002/dmrr.3029

Peng, H., Pan, S., Yan, Y., Brand, R. E., Petersen, G. M., Chari, S. T., et al. (2020). Systemic Proteome Alterations Linked to Early Stage Pancreatic Cancer in Diabetic Patients. Cancers (Basel) 12 (6), 1534. doi:10.3390/cancers12061534

$\mathrm{Pu}$, J., Shen, J., Zhong, Z., Yanling, M., and Gao, J. (2020). KANK1 Regulates Paclitaxel Resistance in Lung Adenocarcinoma A549 Cells. Artif. Cell Nanomed Biotechnol 48 (1), 639-647. doi:10.1080/21691401.2020.1728287

Radgonde, A., Liran, T., and Jacob, P. (2018). Leucine-rich a-2-glyco-protein-1 (LRG-1) Expression in Retinoblastoma. Invest. Ophthalmol. Vis. Sci. 59 (2), 685-692.

Rainer, T. H., Leung, L. Y., Chan, C., Leung, Y. K., Cheng, N. M., Lai, P., et al. (2017). Circulating Human Leucine-Rich $\alpha$-2-glycoprotein 1 mRNA and Protein Levels to Detect Acute Appendicitis in Patients with Acute Abdominal Pain. Clin. Biochem. 50 (9), 485-490. doi:10.1016/ j.clinbiochem.2017.02.010

Razmkhah, F., Ghasemi, S., Soleimani, M., and Amini Kafi-Abad, S. (2019). LY86, LRG1 and PDE9A Genes Overexpression in Umbilical Cord Blood Hematopoietic Stem Progenitor Cells by Acute Myeloid Leukemia (M3) Microvesicles. Exp. Hematol. Oncol. 8, 23. doi:10.1186/s40164-0190147-8

Shimizu, M., Inoue, N., Mizuta, M., Nakagishi, Y., and Yachie, A. (2019). Serum Leucine-Rich a2-Glycoprotein as a Biomarker for Monitoring Disease Activity in Patients with Systemic Juvenile Idiopathic Arthritis. J. Immunol. Res. 2019, 3140204. doi:10.1155/2019/3140204

Shimizu, M., Nakagishi, Y., Inoue, N., Mizuta, M., and Yachie, A. (2017). Leucinerich a2-glycoprotein as the Acute-phase Reactant to Detect Systemic Juvenile Idiopathic Arthritis Disease Activity during Anti-interleukin-6 Blockade Therapy: A Case Series. Mod. Rheumatol. 27 (5), 833-837. doi:10.1080/ 14397595.2016.1270795

Shinozaki, E., Tanabe, K., Akiyoshi, T., Tsuchida, T., Miyazaki, Y., Kojima, N., et al. (2018). Serum Leucine-Rich Alpha-2-Glycoprotein-1 with Fucosylated Triantennary N-Glycan: a Novel Colorectal Cancer Marker. BMC Cancer 18 (1), 406. doi:10.1186/s12885-018-4252-6

Shinzaki, S., Matsuoka, K., Iijima, H., Mizuno, S., Serada, S., Fujimoto, M., et al. (2017). Leucine-rich Alpha-2 Glycoprotein Is a Serum Biomarker of Mucosal Healing in Ulcerative Colitis. J. Crohns Colitis 11 (1), 84-91. doi:10.1093/eccojcc/jjw132

Shinzaki, S., Matsuoka, K., Tanaka, H., Takeshima, F., Kato, S., Torisu, T., et al. (2021). Leucine-rich Alpha-2 Glycoprotein Is a Potential Biomarker to Monitor Disease Activity in Inflammatory Bowel Disease Receiving Adalimumab: PLANET Study. J. Gastroenterol. 56 (6), 560-569. doi:10.1007/s00535-02101793-0

Singh, H., Yu, Y., Suh, M. J., Torralba, M. G., Stenzel, R. D., Tovchigrechko, A., et al. (2017). Type 1 Diabetes: Urinary Proteomics and Protein Network Analysis Support Perturbation of Lysosomal Function. Theranostics 7 (10), 2704-2717. doi:10.7150/thno.19679
Sng, M. K., Chan, J. S. K., Teo, Z., Phua, T., Tan, E. H. P., Wee, J. W. K., et al. (2018). Selective Deletion of PPAR $\beta / \delta$ in Fibroblasts Causes Dermal Fibrosis by Attenuated LRG1 Expression. Cell Discov 4, 15. doi:10.1038/s41421-0180014-5

Song, S., Cheng, J., Yu, B. J., Zhou, L., Xu, H. F., and Yang, L. L. (2020). LRG1 Promotes Corneal Angiogenesis and Lymphangiogenesis in a Corneal Alkali Burn Mouse Model. Int. J. Ophthalmol. 13 (3), 365-373. doi:10.18240/ ijo.2020.03.01

Su, Q., Lv, X. W., Sun, Y. H., Ye, Z. L., Kong, B. H., and Qin, Z. B. (2019). MicroRNA-494 Inhibits the LRG1 Expression to Induce Proliferation and Migration of VECs in Rats Following Myocardial Infarction. Mol. Ther. Nucleic Acids 18, 110-122. doi:10.1016/j.omtn.2019.08.007

Sun, D. C., Shi, Y., Wang, L. X., Lv, Y., Han, Q. L., Wang, Z. K., et al. (2017). Leucine-rich Alpha-2-Glycoprotein-1, Relevant with Microvessel Density, Is an Independent Survival Prognostic Factor for Stage III Colorectal Cancer Patients: a Retrospective Analysis. Oncotarget 8 (39), 66550-66558. doi:10.18632/oncotarget.16289

Sun, Y., Wang, F., Zhou, Z., Teng, J., Su, Y., Chi, H., et al. (2020). Urinary Proteomics Identifying Novel Biomarkers for the Diagnosis of Adult-Onset Still's Disease. Front. Immunol. 11, 2112. doi:10.3389/fimmu.2020.02112

Takahashi, N., Takahashi, Y., and Putnam, F. W. (1985). Periodicity of Leucine and Tandem Repetition of a 24-amino Acid Segment in the Primary Structure of Leucine-Rich Alpha 2-glycoprotein of Human Serum. Proc. Natl. Acad. Sci. U S A. 82 (7), 1906-1910. doi:10.1073/pnas.82.7.1906

Tonry, C., McDonald, K., Ledwidge, M., Hernandez, B., Glezeva, N., Rooney, C., et al. (2021). Multiplexed Measurement of Candidate Blood Protein Biomarkers of Heart Failure. ESC Heart Fail. 8 (3), 2248-2258. doi:10.1002/ehf2.13320

Travis, M. A., and Sheppard, D. (2014). TGF- $\beta$ Activation and Function in Immunity. Annu. Rev. Immunol. 32, 51-82. doi:10.1146/annurev-immunol032713-120257

Urushima, H., Fujimoto, M., Mishima, T., Ohkawara, T., Honda, H., Lee, H., et al. (2017). Leucine-rich Alpha 2 Glycoprotein Promotes Th17 Differentiation and Collagen-Induced Arthritis in Mice through Enhancement of TGF- $\beta$-Smad2 Signaling in Naïve Helper T Cells. Arthritis Res. Ther. 19 (1), 137. doi:10.1186/ s13075-017-1349-2

Verweyen, E. L., Pickering, A., Grom, A. A., and Schulert, G. S. (2021). Distinct Gene Expression Signatures Characterize Strong Clinical Responders versus Nonresponders to Canakinumab in Children with Systemic Juvenile Idiopathic Arthritis. Arthritis Rheumatol. 73 (7), 1334-1340. doi:10.1002/art.41640

Wang, S., Wang, E., Chen, Q., Yang, Y., Xu, L., Zhang, X., et al. (2021). Uncovering Potential lncRNAs and mRNAs in the Progression from Acute Myocardial Infarction to Myocardial Fibrosis to Heart Failure. Front. Cardiovasc. Med. 8, 664044. doi:10.3389/fcvm.2021.664044

Wang, X., Abraham, S., McKenzie, J. A. G., Jeffs, N., Swire, M., Tripathi, V. B., et al. (2013). LRG1 Promotes Angiogenesis by Modulating Endothelial TGF- $\beta$ Signalling. Nature 499 (7458), 306-311. doi:10.1038/nature12345

Wang, Y., Xing, Q., Chen, X., Wang, J., Guan, S., Chen, X., et al. (2019). The Clinical Prognostic Value of LRG1 in Esophageal Squamous Cell Carcinoma. Curr. Cancer Drug Targets 19 (9), 756-763. doi:10.2174/ 1568009619666190204095942

Wang, Y., Chen, C., Hua, Q., Wang, L., Li, F., Li, M., et al. (2017a). Downregulation of Leucine-rich- $\alpha$-2-glycoprotein 1 Expression is Associated with the Tumorigenesis of Head and Neck Squamous Cell Carcinoma. Oncol. Rep. 37 (3), 1503-1510. doi:10.3892/or.2017.5377

Wang, Y., Xu, J., Zhang, X., Wang, C., Huang, Y., Dai, K., et al. (2017b). TNFa-induced LRG1 Promotes Angiogenesis and Mesenchymal Stem Cell Migration in the Subchondral Bone during Osteoarthritis. Cell Death Dis 8 (3), e2715. doi:10.1038/cddis.2017.129

Wu, J., Yin, H., Zhu, J., Buckanovich, R. J., Thorpe, J. D., Dai, J., et al. (2015). Validation of LRG1 as a Potential Biomarker for Detection of Epithelial Ovarian Cancer by a Blinded Study. PLoS One 10 (3), e0121112. doi:10.1371/ journal.pone.0121112

Xiao, S., and Zhu, H. (2018). Leucine-Rich Alpha-2-Glycoprotein1 Gene Interferes with Regulation of Apoptosis in Leukemia KASUMI-1 Cells. Med. Sci. Monit. 24, 8348-8356. doi:10.12659/MSM.911249

Xiao, S. J., Zhou, Y. F., Wu, Q., Ma, W. R., Chen, M. L., and Pan, D. F. (2021). Uncovering the Differentially Expressed Genes and Pathways Involved in the Progression of Stable Coronary Artery Disease to Acute Myocardial Infarction 
Using Bioinformatics Analysis. Eur. Rev. Med. Pharmacol. Sci. 25 (1), 301-312. doi:10.26355/eurrev_202101_24396

Xie, X. F., Chu, H. J., Xu, Y. F., Hua, L., Wang, Z. P., Huang, P., et al. (2019). Proteomics Study of Serum Exosomes in Kawasaki Disease Patients with Coronary Artery Aneurysms. Cardiol. J. 26 (5), 584-593. doi:10.5603/ CJ.a2018.0032

Xie, Z. B., Zhang, Y. F., Jin, C., Mao, Y. S., and Fu, D. L. (2019). LRG-1 Promotes Pancreatic Cancer Growth and Metastasis via Modulation of the EGFR/p38 Signaling. J. Exp. Clin. Cancer Res. 38 (1), 75. doi:10.1186/s13046-019-1088-0

Xuan, C., Li, H., Li, L. L., Tian, Q. W., Wang, Q., Zhang, B. B., et al. (2019). Screening and Identification of Pregnancy Zone Protein and Leucine-Rich Alpha-2-Glycoprotein as Potential Serum Biomarkers for Early-Onset Myocardial Infarction Using Protein Profile Analysis. Proteomics Clin. Appl. 13 (3), e1800079. doi:10.1002/prca.201800079

Yamamoto, M., Takahashi, T., Serada, S., Sugase, T., Tanaka, K., Miyazaki, Y., et al. (2017). Overexpression of Leucine-Rich a2-glycoprotein-1 Is a Prognostic Marker and Enhances Tumor Migration in Gastric Cancer. Cancer Sci. 108 (10), 2052-2060. doi:10.1111/cas.13329

Yanagimachi, M., Fukuda, S., Tanaka, F., Iwamoto, M., Takao, C., Oba, K., et al. (2021). Leucine-rich Alpha-2-Glycoprotein 1 and Angiotensinogen as Diagnostic Biomarkers for Kawasaki Disease. PLoS One 16 (9), e0257138. doi:10.1371/journal.pone.0257138

Yang, F. J., Hsieh, C. Y., Shu, K. H., Chen, I. Y., Pan, S. Y., Chuang, Y. F., et al. (2020). Plasma Leucine-Rich a-2-Glycoprotein 1 Predicts Cardiovascular Disease Risk in End-Stage Renal Disease. Sci. Rep. 10 (1), 5988. doi:10.1038/ s41598-020-62989-7

Yang, N., Wang, H., Zhang, W., Sun, H., Li, M., Xu, Y., et al. (2021). Integrated Analysis of Transcriptome and Proteome to Explore the Genes Related to Steroid-Induced Femoral Head Necrosis. Exp. Cel Res 401 (1), 112513. doi:10.1016/j.yexcr.2021.112513

Yang, Y., Luo, R., Cheng, Y., Liu, T., Dai, W., Li, Y., et al. (2020). Leucinerich a2-glycoprotein-1 Upregulation in Plasma and Kidney of Patients with Lupus Nephritis. BMC Nephrol. 21 (1), 122. doi:10.1186/s12882020-01782-0

Yap, T. L., Fan, J. D., Chen, Y., Ho, M. F., Choo, C. S., Allen, J., et al. (2019). A Novel Noninvasive Appendicitis Score with a Urine Biomarker. J. Pediatr. Surg. 54 (1), 91-96. doi:10.1016/j.jpedsurg.2018.10.025

Yu, B., Yang, L., Song, S., Li, W., Wang, H., and Cheng, J. (2021). LRG1 Facilitates Corneal Fibrotic Response by Inducing Neutrophil Chemotaxis via Stat3 Signaling in Alkali-Burned Mouse Corneas. Am. J. Physiol. Cel Physiol 321 (3), C415-c28. doi:10.1152/ajpcell.00517.2020

Yu, J., Zhang, J., Su, X. T., and Han, Y. Q. (2019). [Expression and Clinical Significance of Serum LRG1 in Patients with Diffuse Large B-Cell Lymphoma before Treatment]. Zhongguo Shi Yan Xue Ye Xue Za Zhi 27 (6), 1850-1855. doi:10.19746/j.cnki.issn.1009-2137.2019.06.023

Yu, R., Zhang, J., Zang, Y., Zeng, L., Zuo, W., Bai, Y., et al. (2019). iTRAQ-based Quantitative Protein Expression Profiling of Biomarkers in Childhood B-Cell and T-Cell Acute Lymphoblastic Leukemia. Cancer Manag. Res. 11, 7047-7063. doi:10.2147/CMAR.S210093

Yu, R. H., Zhang, J. Y., Liu, Y. F., and Zhu, Z. M. (2021). [Screening Serum Differential Proteins in Children with Acute Promyelocytic Leukemia Based on iTRAQ Technique]. Zhongguo Shi Yan Xue Ye Xue Za Zhi 29 (5), 1462-1470. doi:10.19746/j.cnki.issn.1009-2137.2021.05.014

Yu, S. J., Kim, H., Min, H., Sohn, A., Cho, Y. Y., Yoo, J. J., et al. (2017). Targeted Proteomics Predicts a Sustained Complete-Response after Transarterial Chemoembolization and Clinical Outcomes in Patients with Hepatocellular Carcinoma: A Prospective Cohort Study. J. Proteome Res. 16 (3), 1239-1248. doi:10.1021/acs.jproteome.6b00833
Zhan, Y., Yang, Y. T., You, H. M., Cao, D., Liu, C. Y., Zhou, C. J., et al. (2014). Plasma-based Proteomics Reveals Lipid Metabolic and Immunoregulatory Dysregulation in post-stroke Depression. Eur. Psychiatry 29 (5), 307-315. doi:10.1016/j.eurpsy.2014.03.004

Zhang, A., Fang, H., Chen, J., He, L., and Chen, Y. (2020). Role of VEGF-A and LRG1 in Abnormal Angiogenesis Associated with Diabetic Nephropathy. Front. Physiol. 11, 1064. doi:10.3389/fphys.2020.01064

Zhang, M., Wang, Y., Wang, J., Li, X., Ma, A., and Pan, X. (2021). Serum LRG1 as a Novel Biomarker for Cardioembolic Stroke. Clin. Chim. Acta 519, 83-91. doi:10.1016/j.cca.2021.04.002

Zhang, N., Ren, Y., Wang, Y., Zhao, L., Wang, B., Ma, N., et al. (2020). LRG1 Suppresses Migration and Invasion of Esophageal Squamous Cell Carcinoma by Modulating Epithelial to Mesenchymal Transition. J. Cancer 11 (6), 1486-1494. doi:10.7150/jca.36189

Zhang, Q., Huang, R., Tang, Q., Yu, Y., Huang, Q., Chen, Y., et al. (2018). Leucinerich Alpha-2-Glycoprotein-1 Is Up-Regulated in Colorectal Cancer and Is a Tumor Promoter. Onco Targets Ther. 11, 2745-2752. doi:10.2147/ OTT.S153375

Zhang, X., Pek, S. L. T., Tavintharan, S., Sum, C. F., Lim, S. C., Ang, K., et al. (2019). Leucine-rich $a$-2-glycoprotein Predicts Proliferative Diabetic Retinopathy in Type 2 Diabetes. J. Diabetes Complications 33 (9), 651-656. doi:10.1016/ j.jdiacomp.2019.05.021

Zhang, Y. S., Han, L., Yang, C., Liu, Y. J., and Zhang, X. M. (2021). Prognostic Value of LRG1 in Breast Cancer: A Retrospective Study. Oncol. Res. Treat. 44 (1-2), 36-42. doi:10.1159/000510945

Zheng, R., Zhang, Z. H., Zhao, Y. X., Chen, C., Jia, S. Z., Cao, X. C., et al. (2019). Transcriptomic Insights into the Response of the Olfactory Bulb to Selenium Treatment in a Mouse Model of Alzheimer's Disease. Int. J. Mol. Sci. 20 (12), 2998. doi:10.3390/ijms20122998

Zhong, M. E., Chen, Y., Xiao, Y., Xu, L., Zhang, G., Lu, J., et al. (2019). Serum Extracellular Vesicles Contain SPARC and LRG1 as Biomarkers of colon Cancer and Differ by Tumour Primary Location. EBioMedicine 50, 211-223. doi:10.1016/j.ebiom.2019.11.003

Zhou, L., Shi, D. P., Chu, W. J., Yang, L. L., and Xu, H. F. (2021). LRG1 Promotes Epithelial-Mesenchymal Transition of Retinal Pigment Epithelium Cells by Activating NOX4. Int. J. Ophthalmol. 14 (3), 349-355. doi:10.18240/ ijo.2021.03.03

Zhou, Y., Zhang, X., Zhang, J., Fang, J., Ge, Z., and Li, X. (2017). LRG1 Promotes Proliferation and Inhibits Apoptosis in Colorectal Cancer Cells via RUNX1 Activation. PLoS One 12 (4), e0175122. doi:10.1371/journal.pone.0175122

Conflict of Interest: The authors declare that the research was conducted in the absence of any commercial or financial relationships that could be construed as a potential conflict of interest.

Publisher's Note: All claims expressed in this article are solely those of the authors and do not necessarily represent those of their affiliated organizations, or those of the publisher, the editors and the reviewers. Any product that may be evaluated in this article, or claim that may be made by its manufacturer, is not guaranteed or endorsed by the publisher.

Copyright $\odot 2022 \mathrm{Zou}, \mathrm{Xu}$, Chen, Wu, Fu and Lv. This is an open-access article distributed under the terms of the Creative Commons Attribution License (CC BY). The use, distribution or reproduction in other forums is permitted, provided the original author(s) and the copyright owner(s) are credited and that the original publication in this journal is cited, in accordance with accepted academic practice. No use, distribution or reproduction is permitted which does not comply with these terms. 